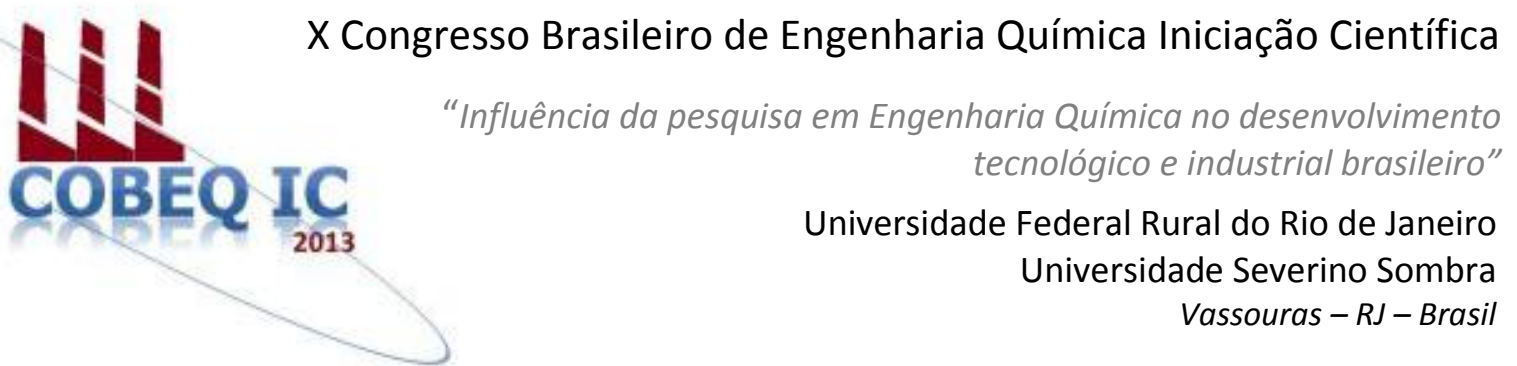

\title{
ESTUDO DA CONTAMINAÇÃO EM FERMENTAÇÃO ALCOÓLICA COM LEVEDURAS FLOCULANTES
}

\author{
SOUSA*11, M.D.B.; CECÍLO**1, M.S.A.; GUIDINI ${ }^{2}$, C.Z.; MARQUEZ ${ }^{3}$, L.D.S.; \\ RIBEIRO ${ }^{3}$, E.J.
}

${ }^{1}$ Aluna da FEQ/UFU $\quad{ }^{2}$ Doutoranda do FEQ/UFU $\quad{ }^{3}$ Professor (a) da FEQ/UFU Faculdade de Engenharia Química - Universidade Federal de Uberlândia Endereço-UFU, Av. João Naves de Ávila, 2121, Campus Santa Mônica - Bloco $1 K, C E P .38400-902, M G$,

email: libia@feq.ufu.br

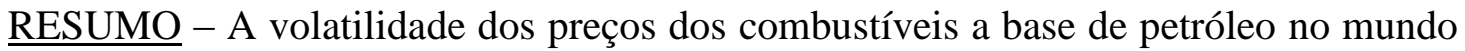
e a segurança do clima brasileiro impulsionam a pesquisa por fontes de energia alternativas e o desenvolvimento de pesquisas em biocombustível para substituição do petróleo desde 1970. O estudo da fermentação alcoólica utilizando leveduras floculantes aparece como uma alternativa à diminuição dos custos desta produção pela facilidade de separação das leveduras do meio fermentado por um processo de decantação. Uma das preocupações é o tratamento das contaminações durante a fermentação, este trabalho estuda o efeito de antibiótico natural em comparação ao antibiótico comercial Kamoran que em alguns casos tem seu uso limitado por restrições à saúde ou a resistências de cepas. Foram realizadas fermentações em bateladas com concentração de $160 \mathrm{~g} / \mathrm{L}$ de sacarose, à temperatura controlada em $32^{\circ} \mathrm{C}$ sem contaminação; com contaminação e sem antibiótico; contaminada e tratada com 3 ppm de Kamoran; e contaminada e tratada com 35 ppm de beta bio, condições dos antibióticos recomendadas pelos fabricantes. Concentrações como: $1 \mathrm{ppm}$ de Kamoran e beta bio nas concentrações de 20 e $45 \mathrm{ppm}$ também foram analisados. As fermentações ocorreram em 10 horas, obtendo-se $92 \%$ de rendimento da fermentação sem contaminação, valor este reduzido a 50\% quando contaminada; $83 \%$ quando tratada com Kamoran (3ppm) e 86,6\% com a utilização do beta bio (35ppm).

Palavras chave: antibiótico, Kamoran, beta bio.

\section{INTRODUÇÃO}

O petróleo sempre teve grande destaque no setor energético nacional e mundial. Entretanto, visando diminuir os problemas ambientais e devido às perspectivas de esgotamento das fontes não renováveis de combustíveis fósseis, o biocombustível surgiu como uma opção mais viável para assegurar um futuro sustentável.

Por volta de 1970, com a crise do petróleo, instaurou-se no Brasil o programa Pró- Álcool, no qual consistia no incentivo à substituição do petróleo pelo etanol. Foi então, que o álcool 
começou a surgir como uma nova alternativa de biocombustível, uma vez que se comparado aos combustíveis fosseis, o etanol apresenta as vantagens de ser uma fonte renovável de energia, que contribui com a redução das emissões de poluentes.

Nesse contexto, o desafio passou a ser a identificação dos gargalos que limitam os processos de fermentação industriais e o desenvolvimento de processos que forneçam alta produção de etanol (Alfenore et al., 2004).

Atualmente, a utilização de leveduras suspensas no meio fermentativo em plantas industriais de produção de etanol é muito ampla. Porém, devido à dificuldade de se operar com altas densidades de leveduras a produção de etanol acaba inevitavelmente sendo mais baixa. Um recurso para o aumento dessa produtividade seria a separação das células por centrifugação e reciclo das mesmas ao reator. Entretanto, os altos investimentos de capital e elevado custo energético de operação das centrífugas estão associados ao custo de tratamento e bombeamento da corrente de reciclo que elevam o custo do produto final e entravam sua aplicação em plantas químicas produtoras de etanol, especialmente em países em desenvolvimento, onde o custo energético é relativamente alto (Xu et al., 2005, Filho, 2007).

A aplicação de cepas floculantes, como por exemplo, a espécie Saccharomyces cerevisae, no processo de fermentação alcoólica vem sendo analisada, uma vez que essas cepas possuem a capacidade de se agregarem espontaneamente e formarem flocos, resultantes da ligação das proteínas com os receptores da superfície celular e da movimentação das células, que se concentram no fundo do reator após a transformação dos açúcares presentes no caldo de cana em álcool.

Dessa maneira, a retenção das células floculantes no reator possibilita sua reutilização, dispensando assim a centrifugação do vinho fermentado e garantindo uma economia em termos de aquisição e manutenção de centrífugas.

Entretanto, dentre os diversos fatores físicos, químicos e microbiológicos que podem afetar a floculação de leveduras, o rendimento da fermentação e a eficiência da conversão de açúcar em etanol (ZHAO et al., 2009, LIMA et al., 2001), uma das preocupações é o tratamento das contaminações durante a fermentação alcóolica.

Com isso, o estudo do efeito de antibióticos naturais bem como os comerciais, se torna um fator importante a ser analisado de modo a contribuir e auxiliar no aumento da produtividade e na redução do custo do processo, promovendo assim a aplicação de cepas floculantes na produção de etanol a nível comercial.

\section{MATERIAIS E MÉTODOS}

Utilizou-se como micro-organismo Saccharomyces cerevisiae com características floculantes, denominada $\mathrm{C} 2 / 00$, doada pelo Centro Pluridisciplinar de Pesquisas Químicas, Biológicas e Agrícolas (CPQBA). Os reagentes utilizados foram todos de grau analítico, com exceção do açúcar, que foi sacarose comercial. A composição do meio para cultivo das leveduras consistiu-se de sacarose comercial (160 g/L), $\mathrm{KH}_{2} \mathrm{PO}_{4}(5 \mathrm{~g} / \mathrm{L})$, $\mathrm{MgSO}_{4} \cdot 7 \mathrm{H}_{2} \mathrm{O}(1 \mathrm{~g} / \mathrm{L}),\left[\mathrm{NH}_{4}\right]_{2} \mathrm{SO}_{4}(2 \mathrm{~g} / \mathrm{L})$ e extrato de levedura (6 g/L) (Pacheco, 2010).

Os experimentos foram realizados no em um fermentador Biostat M ( B. Braun Co., Alemanha) operado em batelada e com volume de $2 \mathrm{~L}$ e operado com $1,5 \mathrm{~L}$ de meio. Este reator é dotado de camisa para recirculação de água proveniente de um banho termostatizado, no qual se manteve a temperatura constante em $32^{\circ} \mathrm{C} \pm 0,2$ em todos os ensaios. $\mathrm{O} \mathrm{pH}$ foi ajustado apenas no inicio da fermentação em 4,5 .

O contaminante foi obtido através da exposição do caldo de cana ao ambiente durante 7 dias, fazendo com que o caldo fosse contaminado naturalmente. Este contaminado foi centrifugado, decantado e a fase (cultura mista) foi armazenada a $5^{\circ} \mathrm{C}$ e depois adicionada ao decantado celular de Saccharomyces cerevisae floculante. O decantado celular utilizado foi de $150 \mathrm{~g}$ o que corresponde a $10 \%(\mathrm{v} / \mathrm{v})$ do reator, esse decantado celular tem uma contaminação de $10^{10} \mathrm{UFC} / \mathrm{mL}$ e concentração de leveduras de $10^{8}$ células $/ \mathrm{mL}$.

Os agentes antibacterianos utilizados nos processos fermentativos foram um antibiótico natural Beta Bio (Hopsteiner Trading (Zhuhai) 
Co., Ltd.), um extrato de lúpulo, predominantemente com $\beta$-ácidos $45 \pm 15 \%$ dissolvido em propileno glicol de grau alimentício $35 \pm 5 \%$ e o antibiótico comercial Kamoran (Química Real Brasil), monoenzima.

Para a verificação da eficiência dos antibióticos foram realizadas fermentações com a levedura floculante sem a presença de bactérias e com a presença de contaminantes. $\mathrm{Na}$ tentativa de controlar a contaminação foram testadas as concentrações 1, 3 e 6 ppm de Kamoran e para o beta bio utilizou as seguintes concentrações: 20, 35 e 45 ppm.

Os processos fermentativos foram acompanhados por análise de açúcares, de etanol e as contagens de células viáveis de bactérias e leveduras. Foram retiradas amostras de $20 \mathrm{~mL}$, nos quais $2 \mathrm{~mL}$ foi utilizado para determinar as contagens de células e o restante centrifugado a $5000 \mathrm{rpm}$ durante $15 \mathrm{~min}$, a sacarose e o etanol do sobrenadante foram realizadas por análise no HPLC (HPLC modelo LC - 20a destaque, Shimadzu, Japão).

\section{RESULTADOS E DISCUSSÕES}

As fermentações realizadas com a Saccharomyces cerevisae com características floculantes em processo batelada a $32^{\circ} \mathrm{C}$ com $10 \%(\mathrm{v} / \mathrm{v})$ de decantado celular alcançou rendimentos altos de $92 \%$, o açúcar de concentração inicial de $160 \mathrm{~g} / \mathrm{L}$ foi totalmente consumido em 10 horas de fermentação com produtividade de 7,84 g/L.h. As concentrações de etanol, sacarose e células de bactérias estão na Figura 1.

Ao contaminar as leveduras com as bactérias do caldo de cana a fermentação ocorreu conforme a Figura 2. Pode observar que a concentração de etanol obtida foi bem menor que quando não tinha contaminação a maior concentração foi de $48,56 \mathrm{~g} / \mathrm{L}$ de etanol enquanto sem contaminação chegou a 78,44 $\mathrm{g} / \mathrm{L}$ de etanol. Assim houve a necessidade de controlar essa contaminação para melhorar o rendimento e produtividade da fermentação alcoólica.

Inicialmente foram realizados testes utilizando o antibiótico comercial Kamoran na concentração indicada pelo fabricante 3 ppm, mostrado na Figura 3, o uso do antibiótico mostrou ser eficiente também no controle da contaminação utilizando leveduras floculantes, obtendo um rendimento de $83 \%$. Foram testados as concentrações de 1 e $6 \mathrm{ppm}$ de Kamoran, na concentração de 1 ppm o rendimento obtido foi muito baixo ficando em $67,42 \%$ e na concentração de 6 ppm o rendimento aumentou para 89,5\% em 10 horas de fermentação e o açúcar residual de $1,45 \mathrm{~g} / \mathrm{L}$ foi menor do que obtido na fermentação de 3 ppm de 21,31 g/L.

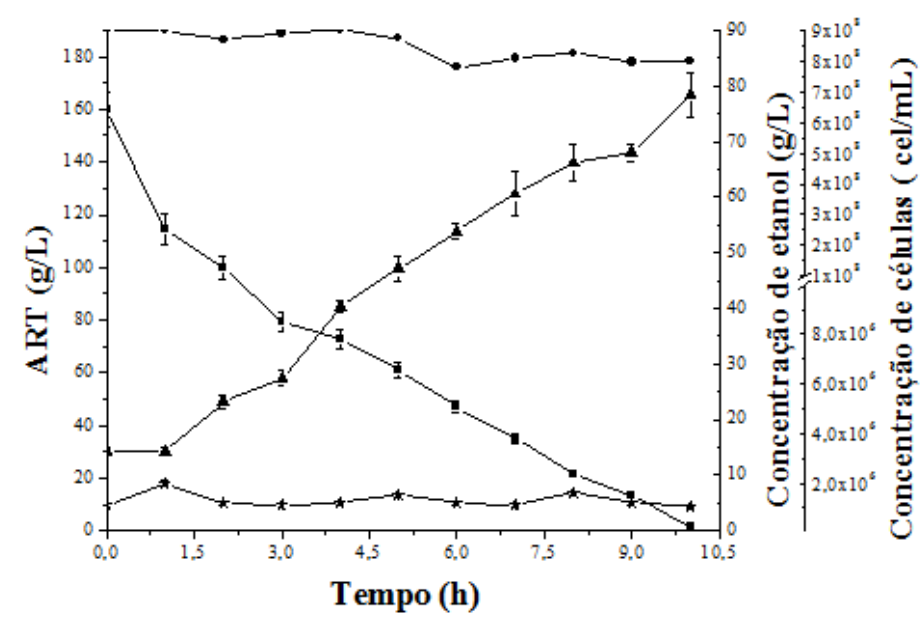

Figura 1 - Fermentação com 160 g/L de sacarose sem contaminação (匹 sacarose, $\Delta$ etanol, • células e bactérias $\mathbf{x})$.

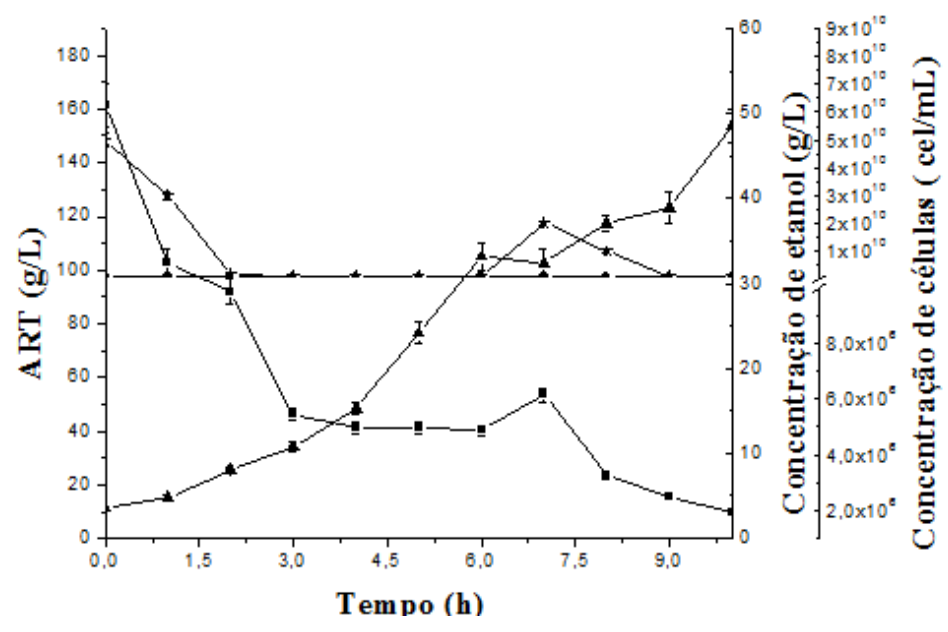

Figura 2 - Fermentação com 160 g/L de sacarose com contaminação ( $\square$ sacarose, $\Delta$ etanol, $\bullet$ células e bactérias $x)$. 


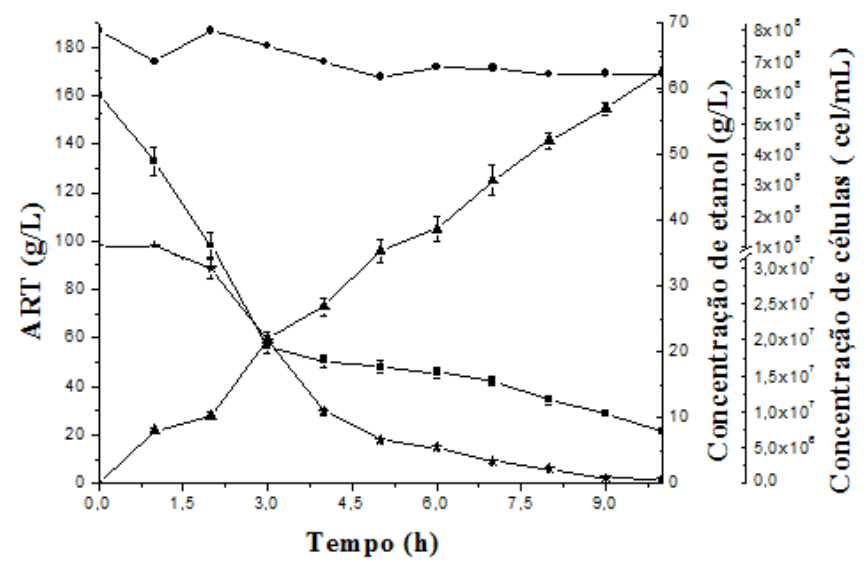

Figura 3 - Fermentação com 160 g/L de sacarose com contaminação e 3 ppm de

Kamoran ( sacarose, $\Delta$ etanol, $\bullet$ células e bactérias $\mathbf{x}$ ).

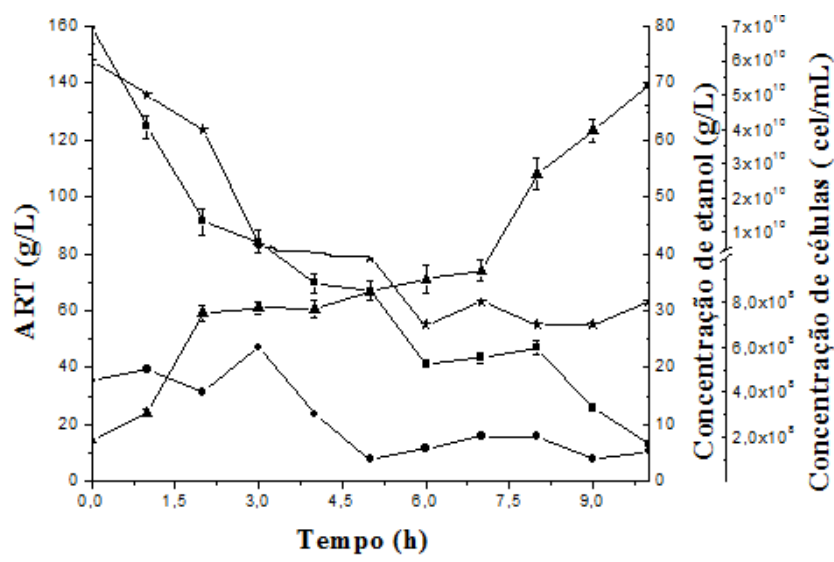

Figura 4 - Fermentação com 160 g/L de sacarose com contaminação e 35 ppm de Beta-Bio (匹 sacarose, $\Delta$ etanol, $\bullet$ células e bactérias $\mathrm{x}$ ).

No intuito de testar a eficiência de um antibiótico natural nas fermentações com leveduras floculantes, foi utilizado o Beta Bio na concentração de 20 ppm, a recomendada pelo fabricante, em $10,5 \mathrm{~h}$ de fermentação ainda restava $8,56 \mathrm{~g} / \mathrm{L}$ de sacarose e obteve apenas 56,27 g/L de etanol, resultando em um rendimento de $68,9 \%$. Por isso aumentou-se a concentração para $35 \mathrm{ppm}$ e o rendimento subiu para $88 \%$ e o comportamento da fermentação esta na Figura 4. Na tentativa de aumentar esse rendimento aumentou-se a concentração de Beta Bio para 45 ppm, mas não houve um aumento significativo de rendimento permanecendo na ordem de $88 \%$ e a diminuição da concentração de células de bactérias reduziu em 10 vezes.
O rendimento obtido por esse trabalho foi promissor e se comparado com o trabalho de Leite et al., 2012 que estudou a influência destes dois antibióticos no controle da contaminação da fermentação com Saccharomyces cerevisae livre pode constatar que o rendimento alcançado com leveduras floculantes foi maior do que com leveduras livres, mas a diminuição da concentração de bactérias e leveduras no trabalho de Leite et al., 2012 foi bem maior chegando a concentrações da ordem de $10^{5}$ células $/ \mathrm{mL}$, enquanto no nosso trabalho tanto as concentrações de leveduras e bactérias não reduziram mais que $10^{7}$ células/mL Isto indica ser a Saccharomyces cerevisae floculante um pouco mais resistentes aos efeitos dos antibióticos.

\section{CONCLUSÃO}

Pode observar que a concentração celular de leveduras não se alterou durante os processos fermentativos. O rendimento da fermentação contaminada com bactérias diminuiu de $92 \%$ para $50 \%$.

Os processos utilizando Kamoran obtiveram resultados satisfatórios, sendo que nas concentrações de 3 e 6 ppm foi obtido rendimentos de 83 e $89,5 \%$, respectivamente. Nas fermentações utilizando o antibiótico natural beta-bio a melhor resposta foi na concentração de $35 \mathrm{ppm}$, atingindo um rendimento de $86,6 \%$. Observa-se que o antibiótico natural teve uma grande atuação no controle da contaminação utilizando leveduras floculantes.

\section{REFERÊNCIAS}

ALFENORE, S., CAMELEYRE, X., BENBADIS, L., BIDEAUX, C., URIBELARREA， J.L., GOMA， G., MOLINA-JOUVE， C., GUILLOUET, S.E. (2004), Aeration strategy: A need for very high ethanol performance in Saccharomyces cerevisiae fed-batch process. Applied Microbiology and Biotechnology, vol. 63, 537-542.

FILHO, U. C. (2007) Engenharia Bioquímica. Uberlândia: Universidade Federal de Uberlândia (apostila). 
LEITE, I.R., FARIA, J.R., MARQUEZ, L.D.S., REIS, M.H.M., RESENDE, M.M., RIBEIRO, E.J., CARDOSO, V.L. (2012), Evaluation of hop extract as a natural antibacterial agent in contaminated fuel ethanol fermentations. Fuel Processing Technology, v.106, 611618.

LIMA, U. A., BASSOL, L. C., AMORIM, H.V. (2001), Biotecnologia Industrial: Processos Fermentativos e Enzimáticos. São Paulo: Edgard Blücher, v.3, 1-43.

PACHECO, T. F. (2010), Fermentação alcoólica com leveduras de características floculantes em reator tipo torre com escoamento ascendente. 94 f. Dissertação (Mestrado em Engenharia Química) Faculdade de Engenharia Química, Universidade Federal de Uberlândia, Uberlândia.

XU, T. J., ZHAO, X. Q., BAI, F. W. (2005), Continuous ethanol production using selfflocculating yeast in a cascade of fermentors. Enzyme and Microbial Technology, v.37, $634-640$.

ZHAO, X. Q., BAI, F. W. (2009), Yeast flocculation: New story in fuel ethanol production. Biotech. Adv., v.27, 849-856.

\section{AGRADECIMENTOS}

Os autores agradecem a FAPEMIG, CNPq e CAPES pelo apoio financeiro. Ao CPQBA pela doação das cepas de levedura. 